\title{
Infection with the dinoflagellate parasite Blastodinium spp. in two Mediterranean copepods
}

\author{
Alf Skovgaard* \\ Departament de Biologia Marina i Oceanografia, Institut de Ciències del Mar, CMIMA, CSIC, \\ Passeig Marítim de la Barceloneta 37-49, 08003 Barcelona, Catalonia, Spain
}

\begin{abstract}
Infection with the intestinal parasite Blastodinium mangini resulted in reduced survival of starved adults of the Mediterranean copepod Oncaea sp. No such effect was measurable for Corycaeus sp. infected by Blastodinium navicula. Both sexes of Oncaea sp. adults were infected by B. mangini and infected copepods were able to mate successfully. However, Oncaea sp. females infected by $B$. mangini did not produce eggs and, thus, appeared to be sterile. By inducing sterility, the harmful effect of $B$. mangini infection on Oncaea sp. populations is bound to be more profound than the effect on the individual level. The mechanism of infection by Blastodinium spp. remains unknown, but uptake of parasite zoospores by Oncaea sp. copepodites concurs with the hypothesis that infection occurs through the ingestion of zoospores by juvenile hosts.
\end{abstract}

KEY WORDS: Copepod · Parasite - Dinoflagellate Blastodinium spp. Oncaea sp. C Corycaeus sp.

Resale or republication not permitted without written consent of the publisher

\section{INTRODUCTION}

Copepods are a key link between microalgal primary production and grazing by larger pelagic organisms in the sea (e.g. Huys \& Boxshall 1991). The marine planktonic food web is, however, not a single-strained food chain in which larger grazers simply feed on smaller organisms; some copepods are carnivores and feed on larger zooplankton organisms (Gophen \& Harris 1984, Ohtsuka \& Kubo 1991) and various microorganisms nourish themselves as parasites on their expected grazers such as copepods (Théodoridès 1989).

Dinoflagellates are particularly well represented among the parasites of copepods (Chatton 1920, Ho \& Perkins 1985), but the consequences of parasitism for natural copepod communities have received little attention. Among the more common parasitic dinoflagellates of copepods in warmer seas are Blastodinium spp. A dozen species have been described that are all specialized inhabitants of the gut of marine planktonic copepods (Chatton 1920, Sewell 1951). The life cycle of Blastodinium spp. is only partially known. Briefly, a copepod is infested by a unicellular stage of the parasite, which then occupies the gut of the copepod, where it grows and develops into a multicellular stage (the trophont) of considerable dimension (up to several $100 \mu \mathrm{m}$ long, depending on the parasite species and size of the host organism). At maturity, numerous zoospores (dinospores) are released through the anus of the host. How the infection of a new host occurs is not known. It is believed that zoospores are ingested and then develop inside the gut of their host instead of being digested (Chatton 1920), but this mode of infection has never been confirmed.

Most Blastodinium species contain chloroplasts (Chatton 1920, Sewell 1951) and are able to perform photosynthesis (Pasternak et al. 1984), but whether the metabolic needs of the photosynthetic species are partly met by heterotrophy remains speculation. Limited information is available on the occurrence and infection frequencies of Blastodinium spp., since few investigations of copepod parasites have been done systematically. Most reports of Blastodinium spp. infections have been made in warm temperate or tropical waters where large proportions of copepods, for the most part adult females, have been found to contain these parasites (summarized by Shields 1994 and Coats 1999). Infection with Blastodinium spp. is 
believed to have no severe physiological effect on the host, since most infected copepods observed have seemed in otherwise good condition, although infected adult females typically have reduced or disintegrated gonads and, consequently, are believed to be sterile (Chatton 1920, Sewell 1951). Based on this pathology, one may categorize Blastodinium spp. as a parasitic castrator rather than a true parasite (Kuris 1974).

The present study addresses the effect of infections by Blastodinium mangini and B. navicula on Oncaea sp. and Corycaeus sp., respectively (Copepoda, Cyclopoida). Species of these copepod genera frequently host Blastodinium spp. (Chatton 1920). While B. mangini predominantly infects Oncaea spp. (Chatton 1920, Sewell 1951), Corycaeus giesbrechti is the sole host of B. navicula (Chatton 1920, as C. venustus). The only exceptions to the latter host-parasite relationship are 2 specimens of $B$. navicula that, with some uncertainty, were found in $O$. venusta in the Arabian Sea (Sewell 1951).

According to Chatton (1920), morphological features of the trophont are important characters for identification of Blastodinium species. The trophont of B. mangini is 200 to $350 \mu \mathrm{m}$ long with a cylindrical to fusiform shape. It is often vaguely curved and has rounded ends. The trophocyte is median to apical in position. The trophont of $B$. navicula is 150 to $200 \mu \mathrm{m}$ long and is symmetrically fusiform with a distended central part and pointed ends. The trophocyte is submedian in position. Both species have brownish pigmentation and are usually gregarious.

\section{MATERIALS AND METHODS}

Sampling. Copepods were collected on August 19 (Oncaea sp.) and 25 (Corycaeus sp.), 2003, off Port Olímpic, Barcelona, Spain (sampling position: $41.22^{\circ} 775^{\prime} \mathrm{N}, 02.13^{\circ} 150^{\prime} \mathrm{E}$; surface water temperature: $26^{\circ} \mathrm{C}$ ). Samples were taken using a $100 \mu \mathrm{m}$ mesh size plankton net pulled vertically from the bottom $(38 \mathrm{~m})$ to the surface. The live animals were kept at $26^{\circ} \mathrm{C}$ and all subsequent handling and experiments were also made at this temperature. On each sampling day, a parallel zooplankton sample was fixed immediately with $10 \%$ borax-buffered formalin and stored at $4{ }^{\circ} \mathrm{C}$ in darkness. Infection frequencies of Blastodinium spp. in the fixed samples were determined by counting hosts with and without parasites using a stereomicroscope. All Corycaeus sp. in the sample were enumerated and dissected. Due to the high abundance of Oncaea sp., this sample was split into 10 equal aliquots of which only 1 was counted. B mangini inside Oncaea sp. was visible without dissection of the animals.

Photographs of live copepods and formalin-fixed parasite trophonts were made using a Canon Power-
Shot G2 digital still camera mounted on an Olympus stereomicroscope or on a Zeiss Axiovert microscope with combined transmitted and epifluorescent illumination (filterset 09). Copepods of the genus Oncaea were identified using species descriptions by Heron \& Bradford-Grieve (1995) and Böttger-Schnack (2001), and Corycaeus by use of the keys by Rose (1933) and Boxshall \& Halsey (2004).

Survival of hosts. The survival times of starved adult copepods were determined to investigate whether Blastodinium spp.-infected individuals had different survival than healthy individuals, i.e. copepods without visible Blastodinium spp. infection. Oncaea sp. adults (148) were isolated, half of which were infected with $B$. mangini, and placed individually in $2 \mathrm{ml} \mathrm{GF} / \mathrm{F}-$ filtered seawater in $3 \mathrm{ml} \mathrm{Falcon}{ }^{\mathrm{TM}}$ multiwell cell culture plates (BD Biosciences). For each treatment (infected versus healthy), 50 copepods were placed in light (approx. $100 \mu \mathrm{mol}$ photons $\mathrm{m}^{-2} \mathrm{~s}^{-1}$ ) and 24 copepods were placed in darkness. For Corycaeus sp., 23 copepods were incubated for each treatment, all in the light. The number of live copepods was then monitored daily by observing each animal independently under a stereomicroscope. Immobile copepods were manipulated carefully with a fine needle to provoke mobility and thereby ascertain whether they were alive. Furthermore, the number of copepods that had produced eggs was noted, and also whether infected copepods had released Blastodinium spp. zoospores. Survival of infected and healthy copepods was analyzed using Kaplan-Meier plots and log-rank tests to compare the survival of 2 populations (SigmaStat ${ }^{\circledR} 3.0$ software, Systat $^{\circledR}$ ). Dead copepods were fixed in formalin for species and sex determination.

Zoospore growth/survival. Experiments were also performed to determine whether Blastodinium mangini zoospores were able to grow or survive outside their hosts and whether Oncaea sp. grazed upon the zoospores. Zoospores for these experiments were obtained by incubating 70 to $80 \mathrm{~B}$. mangini-infected Oncaea sp. for $24 \mathrm{~h}$ in a few $\mathrm{ml}$ of filtered seawater. After this incubation, the suspension of released zoospores was collected with a pipette. Aliquots containing 400 zoospores $\mathrm{ml}^{-1}$ were distributed into six $20 \mathrm{ml}$ glass vials of which 3 were incubated in darkness and 3 were incubated in the light (approx. $100 \mu \mathrm{mol}$ photons $\mathrm{m}^{-2} \mathrm{~s}^{-1}$ ). The concentration of zoospores was then monitored daily for $8 \mathrm{~d}$ by retrieving $1 \mathrm{ml}$ from each vial and counting the number of cells after fixation in Lugol's solution, using an inverted microscope.

Grazing on zoospores. In order to see whether healthy Oncaea sp. grazed upon Blastodinium mangini zoospores, a suspension of zoospores in filtered seawater was incubated for $24 \mathrm{~h}$ in 5 different treatments that all consisted of $2 \mathrm{ml}$ of zoospore sus- 
pension (300 cells $\mathrm{ml}^{-1}$ ) contained in $3 \mathrm{ml}$ wells (Falcon $^{\mathrm{TM}}$ multiwell plates). The 5 treatments were: one with 2 adult Oncaea sp. females, one with 5 Oncaea sp. copepodites (cII-cIII, judged from their size), and one with 10 Oncaea sp. nauplii. The remaining 2 treatments consisted of one control without potential grazers and another with 2 Acartia grani females. The latter served as a 'positive control' to ensure that the experimental set-up was adequate to prove the occurrence of zoospore uptake. All treatments were set up in triplicate. A. grani originated from the culture collection at the Institut de Ciències del Mar, Barcelona, Spain. Oncaea sp. adults, copepodites and nauplii came from a temporary culture reared on a mixture of the dinoflagellate Oxyrrhis marina and the cryptophyte Rhodomonas salina. This culture, however, only survived for a few months, presumably because the food items were not adequate or because the copepods fed on their own offspring. Finally, a fraction of this temporary culture was transferred to a $600 \mathrm{ml}$ culture tissue bottle, which then received a suspension of B. mangini zoospores within a day after these had been released from a dozen freshly collected infected Oncaea sp. In order to see whether the addition of zoospores would lead to visible infection in previously uninfected hosts, this subculture was checked daily by observing the copepods inside the culture tissue bottle using a stereomicroscope equipped with darkfield illumination.

\section{RESULTS}

\section{Identification of Blastodinium spp.}

When viewed with a stereomicroscope with transmitted bright-field illumination, infection of Blastodinium mangini in live Oncaea sp. was relatively easily recognized as one or more dark brownish-greenish bodies, trophonts, in the copepod's gut (Fig. 1A). Recognition was facilitated by use of dark-field illumination by which the parasite trophonts gained a distinctive yellowish colouration (Fig. 1B). Dissection of infected Oncaea sp. revealed the typical, slightly fusiform, shape of the B. mangini trophont (Fig. 1C). The ends of the trophonts were rounded and the trophocytes were median to apical in position (apical in Fig. 1C). Each infected host usually had 2 to 4 trophonts. Due to the chloroplasts they contained, the parasites exhibited red autofluorescence when viewed under epifluorescence microscopy, which assisted in detecting and confirming $B$. mangini infection without
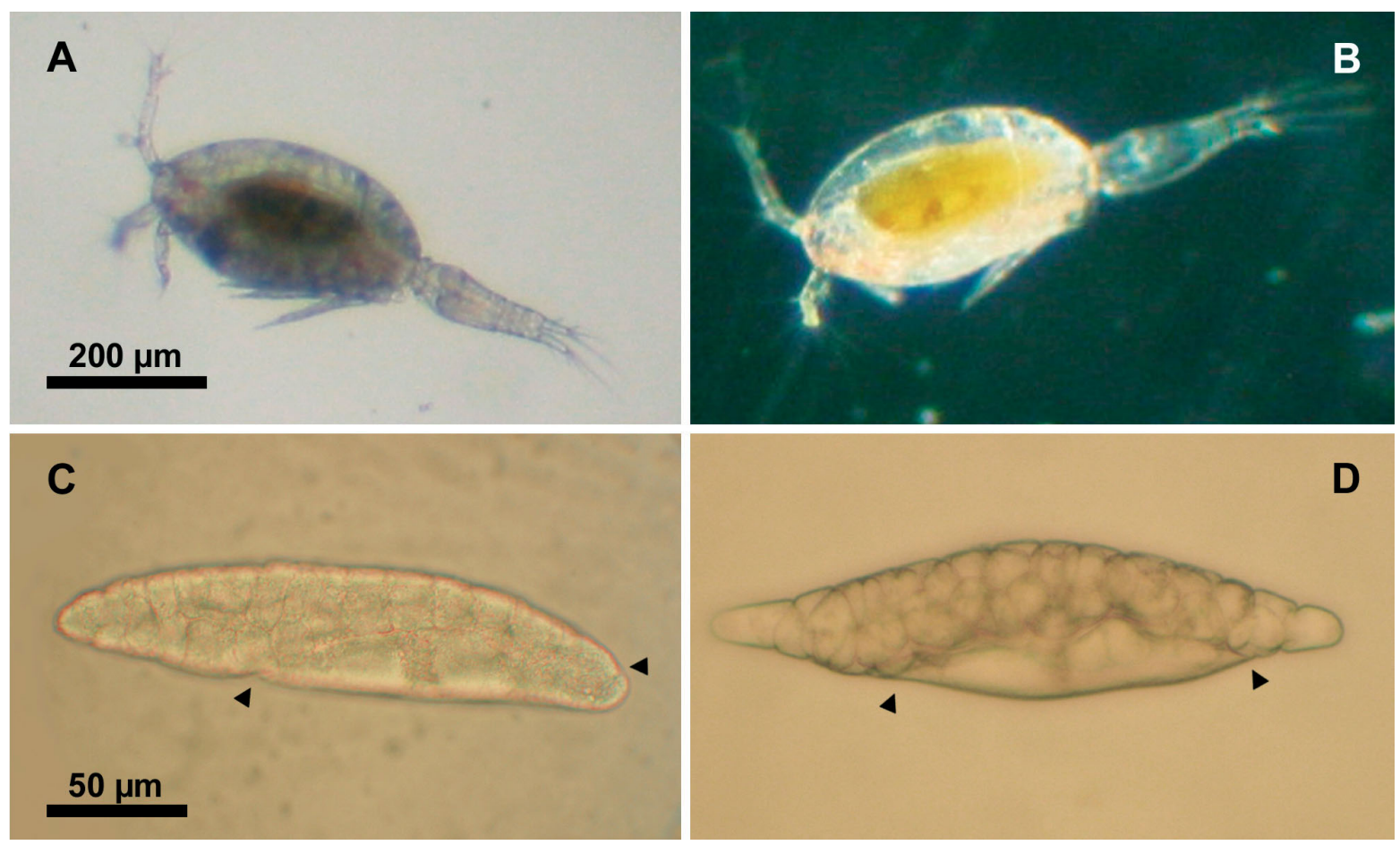

Fig. 1. (A,B) Blastodinium mangini in Oncaea sp., live organisms. (A) Bright-field image of infected female. (B) Dark-field image of infected female; 2 to $3 \mathrm{~B}$. mangini trophonts are visible as yellowish rods inside the copepod's gut. (C,D) Formalin-fixed Blastodinium spp. trophonts. Colour has disappeared due to fixation. (C) B. mangini isolated from its host, Oncaea sp. (D) B. navicula isolated from Corycaeus giesbrechti. Arrowheads point to the extremes of trophocytes. (A) and (B) are of equal magnification, and (C) and (D) are of equal magnification 
dissection of the hosts (Fig. 2). The characteristic colours and fluorescence of Blastodinium spp. was, however, only easily visible in fresh (live) hosts or in formalin-fixed hosts that had been stored cold (at $4^{\circ} \mathrm{C}$ ) in darkness. In formalin-fixed hosts that had been stored at room temperature and exposed to daylight for longer periods, parasites were difficult to discern due to poor preservation of chlorophyll, and the contour of the parasites was the only characteristic whereby they could be distinguished. Total infection frequency of Oncaea sp. in the parallel formalin-fixed sample was $2.0 \%$ (792 copepods). For adult females, males and
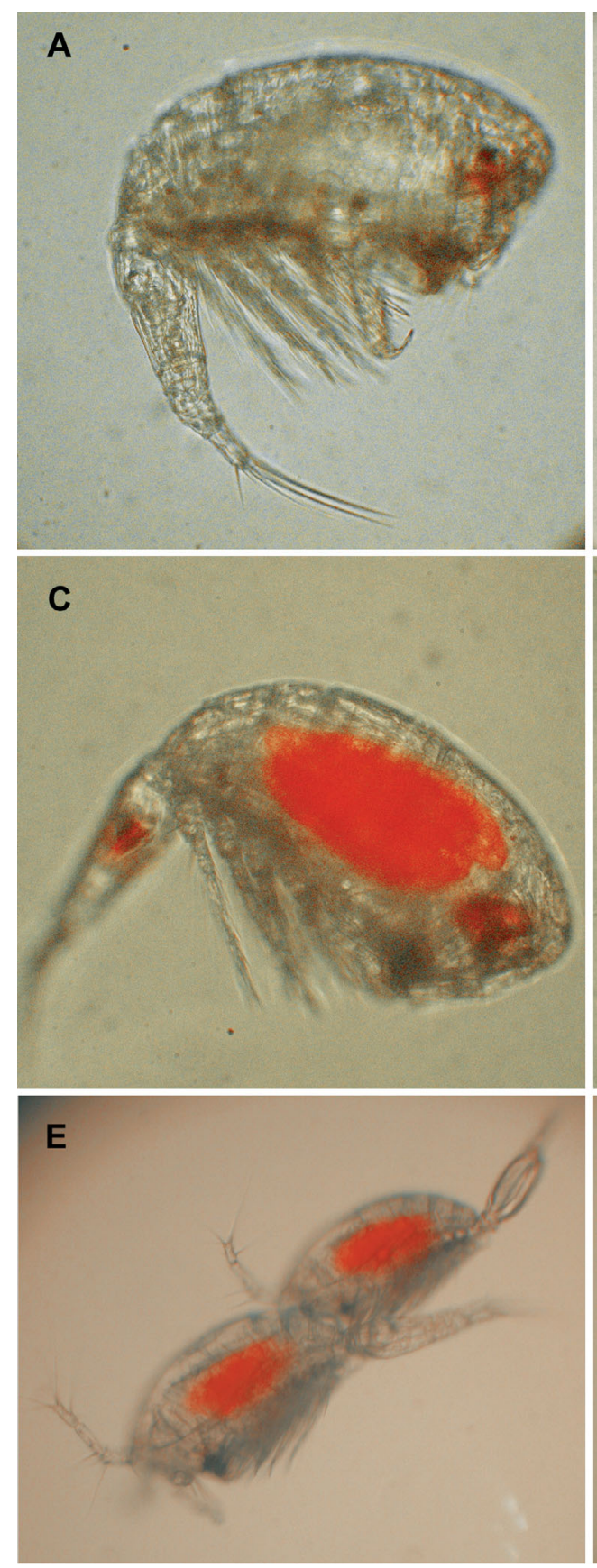
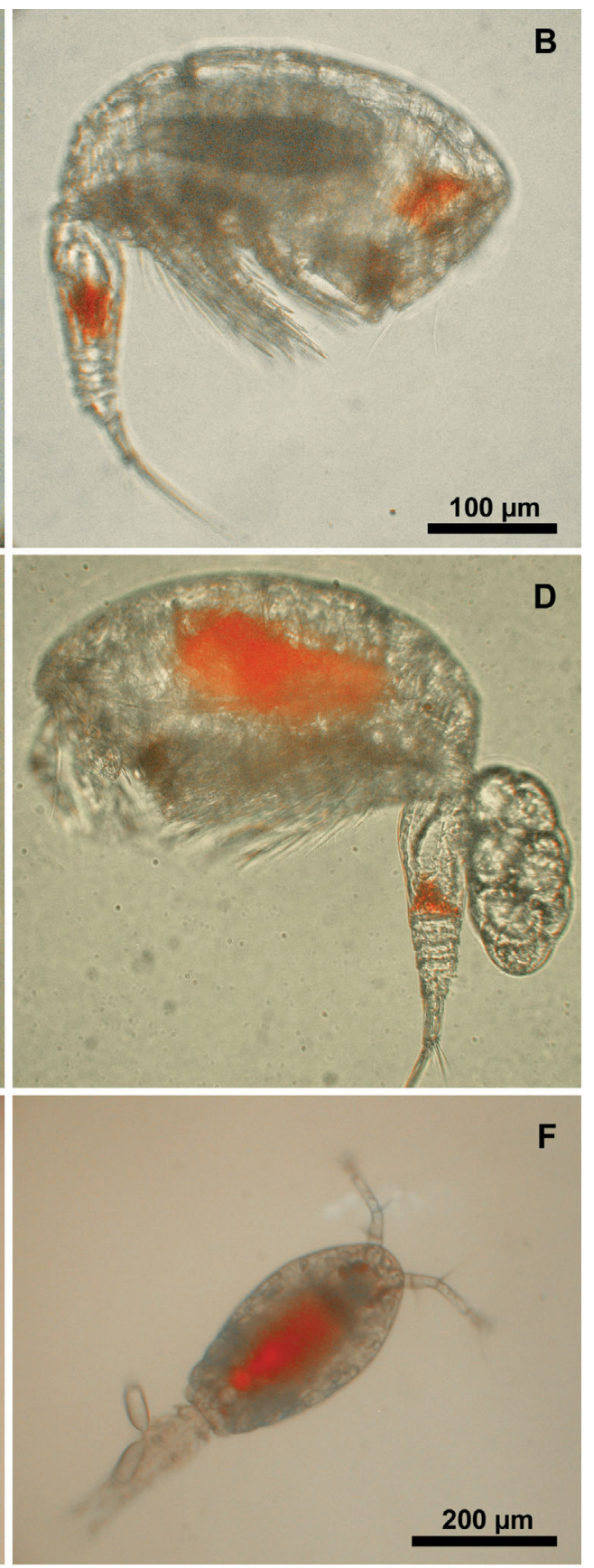

Fig. 2. Oncaea sp. infected with Blastodinium mangini, live organisms. (A) Non-infected female. (B) Infected female, B. mangini trophonts visible as dark rods in the gut of the host. (C) Same specimen as (B), but viewed with epifluorescence microscopy illustrating chlorophyll content of 4 parasite trophonts. (D) Female B. mangini-infected Oncaea sp. carrying eggs. Epifluorescence microscopy. (E) Copulating Oncaea sp. couple in which both parts are infected with B. mangini. Epifluorescence microscopy. (F) Infected Oncaea sp. female with attached spermatophores. Epifluorescence microscopy. (A) to (D) are of equal magnification, and $(\mathrm{E})$ and $(\mathrm{F})$ are of equal magnification 
late-stage copepodites the infection frequencies were $3.7,1.5$ and $1.1 \%$, respectively.

The Corycaeus sp. specimens from the experiment, which were examined for species determination, were all C. giesbrechti. All Blastodinium sp.-infected Corycaeus sp. recognized in the formalin-fixed sample were, likewise, C. giesbrechti, and in all cases the parasite had the size and shape of the trophont characteristic for B. navicula, i.e. the shape was symmetric with pointed ends and the trophocyte was close to median in position (Fig. 1D). There was always more than one trophont in each infected host. Five out of 51 adult Corycaeus sp. in the quantitative, formalin-fixed sample were infected by $B$. navicula. Due to the opaqueness of the fixed host, these parasites were barely recognizable without dissecting the copepod even when the sample had been stored cold and dark.

\section{Survival of hosts}

Oncaea sp. infected with Blastodinium mangini lived significantly shorter than healthy Oncaea sp. (Fig. 3, Table 1). Healthy, starved Oncaea sp. stayed alive on average $10.7 \mathrm{~d}$, whereas $B$. mangini-infected individuals survived on average only $7.4 \mathrm{~d}$. Median survival time for healthy and infected Oncaea sp. was 10 and $7 \mathrm{~d}$, respectively. When comparing healthy and $B$. mangini-infected copepods separately, there was no difference in survival times with respect to whether

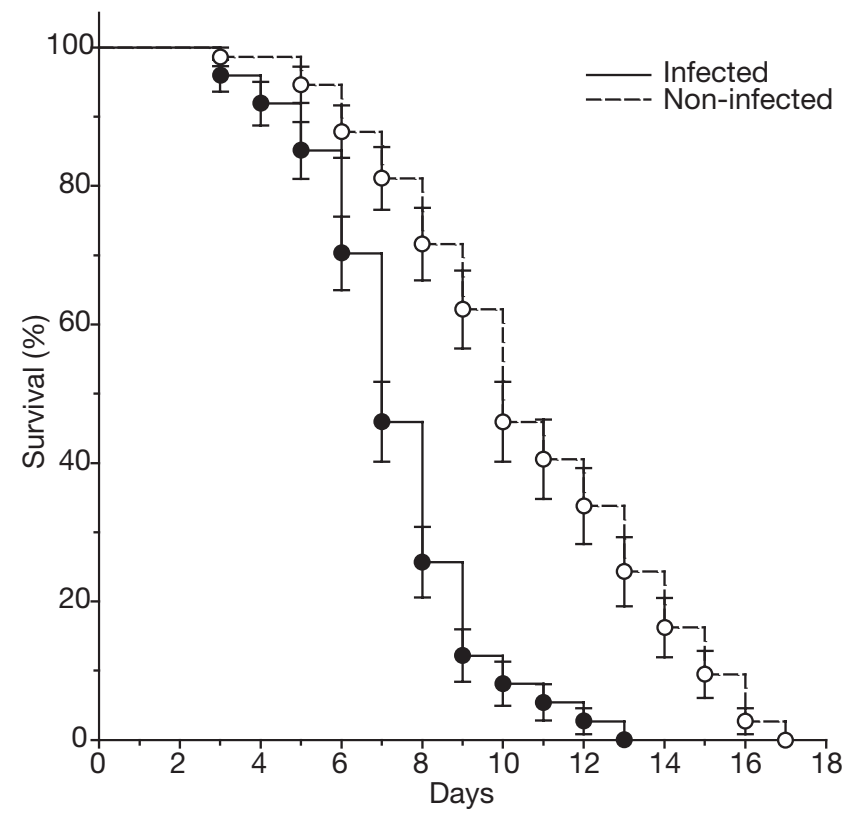

Fig. 3. Kaplan-Meier survival curves of Blastodinium mangini-infected $(\bullet)$ and healthy (non-infected, O) Oncaea sp. Initial number of copepods was 74 from each treatment. Error bars represent $\pm \mathrm{SE}$
Table 1. Survival of starved Oncaea sp. and Corycaeus sp. infected with Blastodinium mangini and B. navicula, respectively, compared with healthy (non-infected) copepods. Different superscript letter denotes that survival curves of populations are statistically different (Kaplan-Meier plots; log rank test, $\mathrm{p}<0.001$ )

\begin{tabular}{|c|c|c|c|c|}
\hline Treatment & $\begin{array}{l}\text { Oncaea sp } \\
\text { Survival time } \\
\text { (d) }\end{array}$ & SE & $\begin{array}{l}\text { Corycaeus } \\
\text { Survival time } \\
\text { (d) }\end{array}$ & $\begin{array}{l}\text { sp. } \\
\text { SE }\end{array}$ \\
\hline \multicolumn{5}{|l|}{ Total } \\
\hline Infected & $7.4^{\mathrm{a}}$ & 0.2 & $2.8^{\mathrm{c}}$ & 0.2 \\
\hline Non-infected & $10.5^{\mathrm{b}}$ & 0.4 & $3.3^{\mathrm{c}}$ & 0.3 \\
\hline \multicolumn{5}{|l|}{ Infected } \\
\hline Light & $7.2^{\mathrm{a}}$ & 0.4 & - & - \\
\hline Dark & $8.1^{\mathrm{a}}$ & 0.4 & - & - \\
\hline \multicolumn{5}{|l|}{ Non-infected } \\
\hline Light & $10.3^{b}$ & 0.5 & - & - \\
\hline Dark & $11.2^{\mathrm{b}}$ & 1.3 & - & - \\
\hline
\end{tabular}

the animals were kept in light or in darkness (Table 1, survival curves not shown).

Mean survival time for healthy and Blastodinium navicula-infected Corycaeus sp. was 3.3 and $2.8 \mathrm{~d}$, respectively (Fig. 4, Table 1) and was, thus, considerably shorter than that of Oncaea sp. There was no significant difference between survival times of healthy versus $B$. navicula-infected individuals of Corycaeus sp. (Fig. 4, Table 1). Median survival time was $4 \mathrm{~d}$ for healthy individuals and $3 \mathrm{~d}$ for infected individuals.

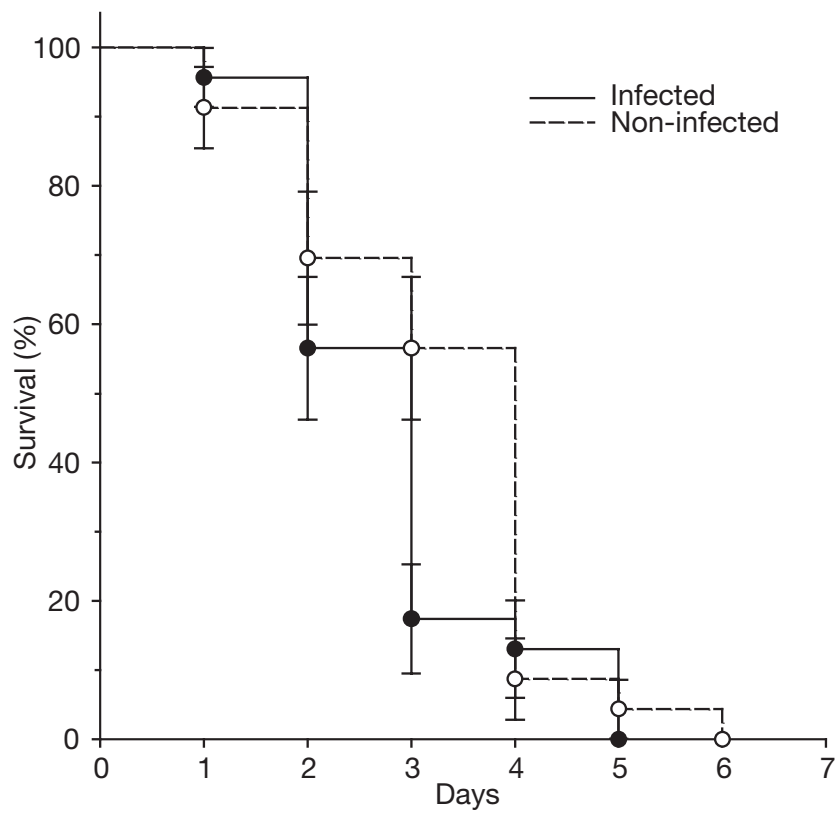

Fig. 4. Kaplan-Meier survival curves of Blastodinium navicula-infected $(\bullet)$ and healthy (non-infected, ○) Corycaeus sp. Initial number of copepods was 23 from each treatment. Error bars represent $\pm \mathrm{SE}$ 


\section{Egg production}

The majority of both healthy and infected Oncaea sp. used for the survival experiment were adult females $(78$ and $54 \%$, respectively), but they did not carry egg sacs when the experiment was initiated. Of the healthy females, $55 \%$ produced eggs within the first $5 \mathrm{~d}$ of the experiment (Fig. 5), whereas none of the infected females produced eggs during the experiment. All but 2 infected Oncaea sp. released zoospores within the first $3 \mathrm{~d}$ of the survival experiment (Fig. 5). The remaining 2 infected copepods never released zoospores, but epifluorescence microscopy confirmed that they were infected (as in Fig. 2C-F). The starved infected animals were, thus, able to stay alive for up to $1 \mathrm{wk}$ after the parasite had completely or partially left the host. On a single occasion a Blastodinium mangini-infected Oncaea sp. female from a field sample was observed to carry eggs (Fig. 2D), but the eggs never hatched. Male and female $B$. mangini-infected Oncaea sp. that had been placed together in filtered seawater in a Petri dish were seen mating on several occasions (Fig. 2E). Some of these females, as well as several infected females collected in the field, had attached spermatophores (Fig. 2F).

\section{Zoospore growth/survival}

Free-swimming Blastodinium mangini zoospores originating from Oncaea sp. did not exhibit photosynthetic growth when incubated in f/2-enriched sea-

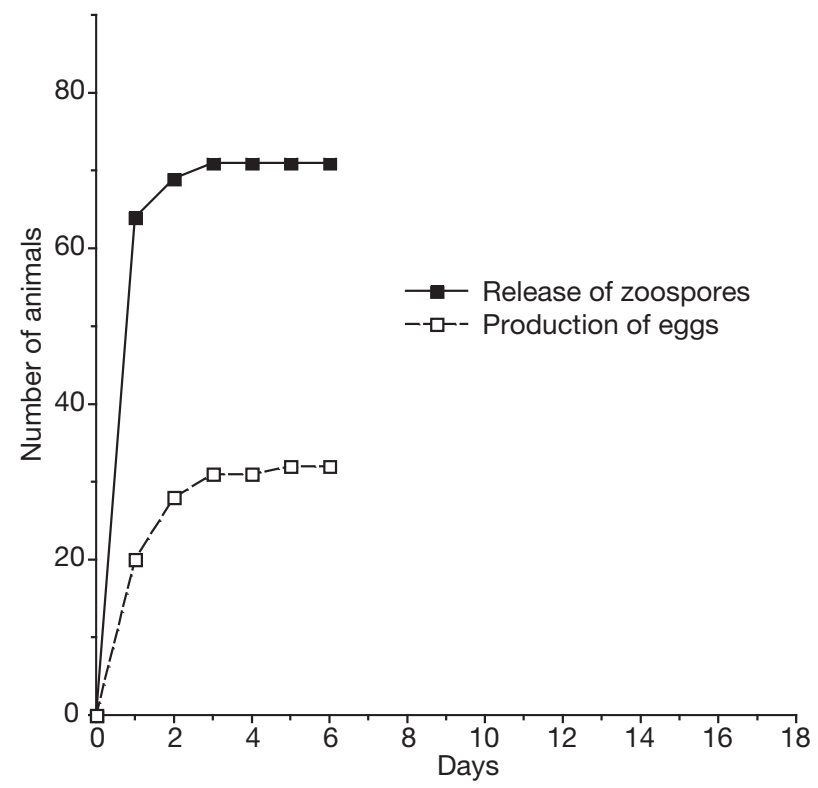

Fig. 5. Cumulative number of Blastodinium mangini-infected Oncaea sp. that had produced zoospores and healthy (noninfected) Oncaea sp. that had produced eggs during the survival experiment shown in Fig. 3 water. Cell numbers declined during the incubation period (Fig. 6), and this decrease was not evidently dependent on whether cells were incubated in light or in darkness.

\section{Grazing on zoospores}

No feeding on zoospores by Oncaea sp. adults or nauplii was detectable, but during the incubation there was a reduction in the number of free-swimming Blastodinium mangini zoospores in the treatments with Oncaea sp. copepodites and Acartia grani (Fig. 7). However, the attempt to induce infection by adding freshly released $B$. mangini zoospores to a temporary Oncaea sp. culture was unsuccessful, since no signs of re-infection were detectable for the time period the Oncaea sp. culture was observed (4 wk).

\section{DISCUSSION}

\section{Taxonomy of parasites and hosts}

All Oncaea sp. used in the experiments had comparable gross morphology. Identification of the specimens was hampered due to their condition (they were dead at the time of fixation). However, the females that were successfully dissected were clearly members of the $O$. media species complex. They were smaller (body length $<0.6 \mathrm{~mm}$ ) than $O$. media and the propor-

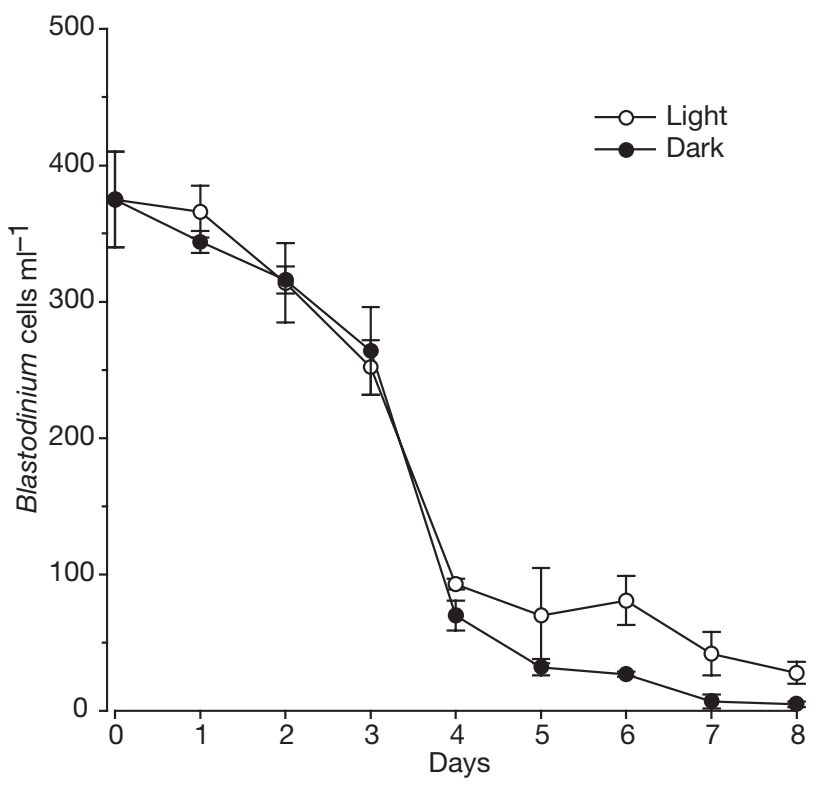

Fig. 6. Development of numbers of Blastodinium mangini zoospores (previously released from Oncaea sp.) incubated in $\mathrm{f} / 2$-medium in the light $\left(100 \mu \mathrm{mol}\right.$ photons $\left.\mathrm{m}^{-2} \mathrm{~s}^{-1}\right)$ and in the dark. Error bars represent $\pm \mathrm{SE}$ 


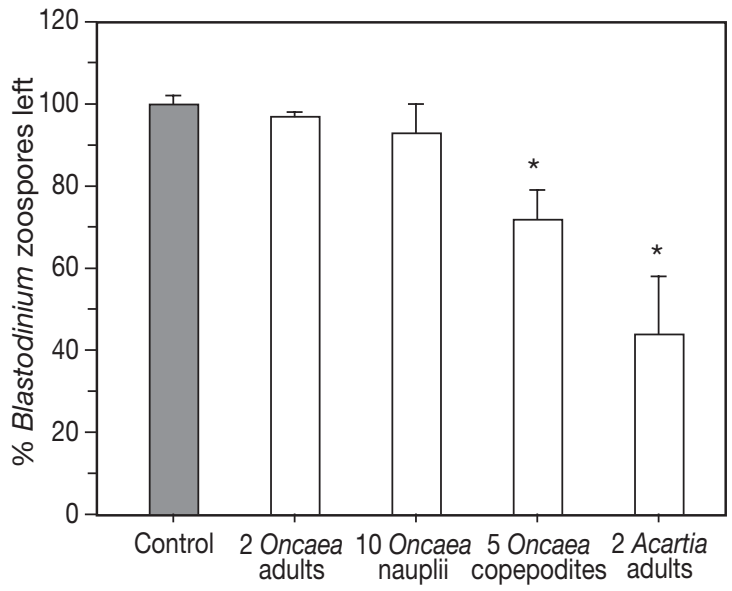

Fig. 7. Potential grazing on Blastodinium mangini zoospores by Oncaea sp. adults, nauplii and copepodites, and by Acartia grani. Error bars represent + SE. *: concentration of zoospores after $24 \mathrm{~h}$ was significantly different from the control without grazers $(t$-test, $\mathrm{p}<0.01)$

tional lengths of their urosome segments indicated a close similarity to the 2 sibling species $O$. scottodicarloi and $O$. waldemari. Other more distinct species of Oncaea were present in low numbers in the collected samples. These were distinguishable due to differences in size and gross morphology, and were not used for the experiments. Dissection of infected specimens (Fig. 1C) confirmed that the parasite of Oncaea sp. was Blastodinium mangini. The size and shape of the trophont as well as the trophocyte location were typical for this species (Chatton 1920). A variety, $B$. mangini var. oncaea, has been described from $O$. media (Chatton 1920). However, it is not always possible to distinguish the variety from the typical form (Sewell 1951) and in the present study no attempt was made to identify $B$. mangini further than to the species level. Neither $O$. scottodicarloi nor $O$. waldemari have been reported as hosts for B. mangini before. However, both species have only recently been recognized as separate species (Bersano \& Boxshall 1994, Heron \& Bradford-Grieve 1995) and they may in the past have been reported as the related species $O$. media (Böttger-Schnack 2001). Further studies are needed to determine exactly which Oncaea species are hosts for Blastodinium spp., incorporating recent knowledge on Oncaea species diversity.

There might have been more than one Corycaeus species in this study since not all animals were dissected and examined for species determination, and the subgenus Onychocorycaeus, to which C. giesbrechti belongs, contains species with gross morphologies comparable to $C$. giesbrechti. At the end of the survival experiment, the state of the parasite of Corycaeus did not allow confirmation of the parasite species due to sporulation and decomposition of the parasite trophont. Species determina- tion of Blastodinium inside a live Corycaeus sp. is not feasible due to the limited transparency of this host species. However, infected Corycaeus sp. specimens that were taken from the parallel, formalin-fixed sample were dissected and all contained the parasite B. navicula. The size and symmetrically pointed shape of the trophont and the submedian location of its trophocyte (Fig. 2D) are all typical characteristics for this species (Chatton 1920). The host was in all cases C. giesbrechti, which is the only member of the subgenus Onychocorycaeus that has been found to host Blastodinium spp. Furthermore, B. navicula is the only Blastodinium species known to infect this subgenus in the Mediterranean Sea (Chatton 1920), and it is therefore plausible that all the infected Corycaeus spp. in this study were $C$. giesbrechti and that the parasite was in all cases B. navicula.

\section{Effects of infection}

The survival experiments validate previous assumptions that infection by Blastodinium spp. is not directly lethal to its hosts (Chatton 1920, Sewell 1951). However, infection by $B$. mangini in Oncaea sp. leads to decreased survival of the host (Fig. 3). This negative effect on survival may be a direct effect on the host's physiology, but it is also possible that infection with Blastodinium spp. reduces the grazing capability of the host or that the parasite exploits the gut content of its host. In the latter 2 cases the negative effect on the host would be indirect by reducing the nutritional uptake of the host. In this respect it would be interesting to study the feeding biology of Blastodinium spp.-infected copepods. No effect of $B$. navicula infection was evident for Corycaeus sp. Since starved Corycaeus sp. only survived for a few days, it is possible that a larger number of animals would be needed to show any effect by the experimental set-up used here. A study on the effect of Blastodinium sp. infection in Eucalanus subtenuis yielded ambiguous results on host survival (Pasternak et al. 1984). However, some copepods in that study became 'heavily overgrown with infusorians' and this might have affected their viability.

One may hypothesize that infection with Blastodinium spp. could have a favourable effect on its host by providing it with photosynthate (Pasternak et al. 1984). This hypothesis is, however, not supported by the results listed in Table 1: starved, infected Oncaea sp. did not benefit from being incubated in the light, where one would have expected that hosting a photosynthetic symbiont would have been an obvious advantage. A similar conclusion may be drawn from the data given by Pasternak et al. (1984), who concluded that the amount of organic matter Blastodinium spp. can deliver to its host is negligible. 


\section{Host sterility}

Previous studies on the fecundity of Blastodinium spp.-infected copepods have been somewhat conflicting. It is generally believed that infected copepod females are sterile or at least have reduced fecundity since they have been observed to have poorly developed or disintegrated ovaries (Chatton 1920, Sewell 1951). However, examples also exist where Blastodinium spp.-infected females have seemed to have normally developed gonads (Ianora et al. 1990). Sterility of Blastodinium spp.-infected females is supported by experimental data in the present study, in which more than half of the incubated healthy females produced eggs within the first $5 \mathrm{~d}$ of incubation (Fig. 5), whereas none of the infected females produced eggs. It is unknown how many of the incubated females were fertilized prior to the experiment, but infected and healthy females may have been fertilized at equal ratios, since infected females are also able to mate (Chatton 1920, Sewell 1951; Fig. 2E,F). Hence, Blastodinium spp.-infected females may mate successfully, but mating does not lead to egg production, probably because the gonads are poorly developed. If infected females do not feed, the lack of egg production may be because the gonads of these females stay immature. This has been shown for a starved calanoid copepod (Niehoff 2000). On rare occasions, Oncaea sp. females infected with $B$. mangini do produce eggs (Fig. 2D). It is possible that the fertility of an infected female is dependent on the developmental stage of the female when it is infected. A female infected at a late developmental stage may, thus, have developed ovaries (Ianora et al. 1990), but a copepod female infected with Blastodinium spp. has never been observed to produce offspring and may, nevertheless, be sterile. Whether a copepod is able to fully recover an infection with Blastodinium spp. and regain its fecundity is a possibility that needs to be investigated. Adult male copepods are generally not infected by Blastodinium spp. (Chatton 1920, Sewell 1951). Oncaea is an exception to this rule, since both adult males and females of this genus are infected by B. mangini (Sewell 1951; Fig. 2E). Whether infected males are fertile is unknown.

\section{Infection via ingestion}

Attempts to induce an infection of dinoflagellate parasites in copepods under laboratory conditions have so far been unsuccessful (Kimmerer \& McKinnon 1990, the present study), and how new hosts are infected remains an enigma. The most plausible hypothesis is that a parasite zoospore is ingested by a copepod and, in the case of Blastodinium spp., develops inside the hosts' gut. A prerequisite for this would be that zoospores are actually ingested by their future host. The feeding biology of Oncaea is not well understood, but some species of the genus are known to be raptorial predators on other zooplankton organisms, in particular appendicularians and their houses (Ohtsuka et al. 1996, Go et al. 1998). Hence, it is unlikely that adults of Oncaea sp. would ingest prey as small as a Blastodinium mangini zoospore (equivalent spherical diameter $\sim 10 \mu \mathrm{m}$ ) and in fact this was not the case in the feeding experiment (Fig. 7). However, the smaller copepodites of Oncaea sp. reduced the number of free-swimming zoospores, and it is possible that parasitism by $B$. mangini is established in juvenile hosts that, probably, depend on food items different from the diet of adults. This would confirm a hypothesis put forward by Chatton (1920) that Blastodinium might infect nauplii and/or early copepodite stages rather than adult copepods. It cannot be excluded, however, that zoospores may enter a new host actively, e.g. through the anus, or that they need to go into a yet unknown life cycle stage (e.g. cysts) to be able to establish a new infection. The possibility also exists that the parasite is transmitted to adult copepods through an intermediate host, but this possibility has never been explored.

\section{CONCLUSION}

Infection with Blastodinium spp. is less drastic for the individual copepod than, e.g., infection with Syndinium, a parasitic dinoflagellate genus that kills its host by literally devouring it from inside (Chatton 1910, Kimmerer \& McKinnon 1990). However, copepods infected with Blastodinium spp. do suffer from reduced fitness and may also have a shorter lifespan in nature. In addition, parasite-induced sterility in females may have considerable effects on the copepod population not only because infected females do not produce eggs, but also because mating with a sterile female is bound to reduce the overall potential for successful mating of healthy males. Sterility of a host may thus have a more important effect on the host population than does the death of the infected host (Kuris 1974). The possible impact of sterile mating in copepods remains to be investigated.

Acknowledgements. I thank E. Saiz for constructive comments and discussion and R. Böttger-Schnack for advice on Oncaea taxonomy. This work was financed by the European Commission, Directorate General Research, through a Marie Curie Postdoctoral fellowship (contract no. HPMF-CT-200201931). 


\section{LITERATURE CITED}

Bersano JGF, Boxshall GA (1994) Planktonic copepods of the genus Oncaea Phillipi (Poecilostomatoida: Oncaeidae) from the waters off southern Brazil. Nauplius, Rio Grande 2:29-41

Böttger-Schnack R (2001) Taxonomy of Oncaeidae (Copepoda, Poecilostomatoida) from the Red Sea. II. Seven species of Oncaea s.str. Bull Nat Hist Mus Lond (Zool) 67: 25-84

Boxshall GA, Halsey SH (2004) An introduction to copepod diversity. The Ray Society, London

Chatton É (1910) Sur l'existence de dinoflagellés cœlomiques. Les Syndinium chez les copépods pélagiques. C R Hebd Séanc Acad Sci Paris 102:645-656

Chatton É (1920) Les Péridiniens parasites. Morphologie, reproduction, éthologie. Arch Zool Exp Gén 59:1-475, plates I-XVIII

Coats DW (1999) Parasitic life styles of marine dinoflagellates. J Eukayot Microbiol 46:402-409

Go YB, Oh BC, Terazaki M (1998) Feeding behavior of the poecilostomatiod copepods Oncaea spp. on chaetognaths. J Mar Syst 15:475-482

Gophen M, Harris RP (1984) Visual predation by a marine cyclopoid copepod, Corycaeus anglicus. J Mar Biol Assoc UK 61:391-399

Heron GA, Bradford-Grieve J (1995) The marine fauna of New Zealand: pelagic Copepoda: Poecilostomatoida: Oncaeidae. N Z Oceanogr Inst Mem 104:1-57

Ho J, Perkins PS (1985) Symbionts of marine copepoda: an overview. Bull Mar Sci 37:586-598

Huys R, Boxshall GA (1991) Copepod evolution. The Ray Society, London

Editorial responsibility: John Dolan,

Villefranche-sur-Mer, France
Ianora A, Scotto di Carlo B, Mazzocchi MG, Mascellaro P (1990) Histomorphological changes in the reproductive condition of parasitized marine planktonic copepods. J Plankton Res 12:249-258

Kimmerer WJ, McKinnon AD (1990) High mortality in a copepod population caused by a parasitic dinoflagellate. Mar Biol 107:449-452

Kuris AM (1974) Trophic interactions: similarity of parasitic castrators to parasitoids. Q Rev Biol 49:129-148

Niehoff B (2000) Effect of starvation on the reproductive potential of Calanus finmarchicus. ICES J Mar Sci 57: $1764-1772$

Ohtsuka S, Kubo N (1991) Larvaceans and their houses as important food for some pelagic copepods. Proc 4 th Int Conf Copepoda, Karuizawa, Japan, 16-20 September 1990. Bull Plankton Soc Jpn Spec Vol:535-551

Ohtsuka S, Böttger-Schnack R, Okada M, Onbé T (1996) In situ feeding habits of Oncaea (Copepoda: Poecilostomatoida) from the upper $250 \mathrm{~m}$ of the central Red Sea, with special reference to consumption of appendicularians houses. Bull Plankton Soc Jpn 43:89-105

Pasternak AF, Arashkevich YG, Sorokin YS (1984) The role of the parasitic algal genus Blastodinium in the ecology of planktonic copepods. Oceanology 24:748-751

Rose M (1933) Copépodes pélagiques. In: Faune de France. Lechevalier, Paris

Sewell RBS (1951) The epibionts and parasites of the planktonic Copepoda of the Arabian Sea. John Murray Expedition 1933-34. Sci Rep Br Mus Nat Hist 9:255-394

Shields JD (1994) The parasitic dinoflagellates of marine crustaceans. Annu Rev Fish Dis 4:241-271

Théodoridès J (1989) Parasitology of marine zooplankton. Adv Mar Biol 25:117-177

Submitted: July 16, 2004; Accepted: November 15, 2004 Proofs received from author(s): January 12, 2005 